\title{
PESQUISA COM ADOLESCENTES E JOVENS SOBRE GESTÃO FINANCEIRA PESSOAL
}

\author{
Sandy Fernanda Ramos Silva Ogeda
}

Faculdade de Tecnologia de São Paulo - FATEC, Presidente Prudente, SP. E-mail: sandy.frso@ hotmail.com

\section{RESUMO}

O presente trabalho tem como tema a gestão financeira pessoal, onde o principal objetivo é identificar o nível de alfabetização financeira dos adolescentes e jovens entre 15 e 21 anos e como eles se comportam em relação a sua renda, consumo e gastos. A escolha deste tema surgiu da necessidade de compreender as principais dúvidas dos adolescentes e jovens adultos no início de suas vidas financeiras, que possuem renda. Pretende-se com essa iniciativa tornar o tema um assunto mais natural e presente, no núcleo familiar bem como abordar o assunto de forma tecnológica em relação ao público-alvo por meio das ferramentas de pesquisa adotadas. Assim sendo, este artigo pretende divulgar os resultados da pesquisa. identificar o nível de alfabetização financeira e relacionar as principais dúvidas dos adolescentes no âmbito da gestão financeira pessoal. Disponibilizamos a pesquisa por meio de um questionário online com a ferramenta Google Forms e o projeto foi apresentado ao público-alvo por meio de instituições parceiras como a Guarda Mirim de Presidente Prudente e pelas redes sociais da pesquisadora. Após a aplicação dos questionários, as respostas foram divididas em dois grupos para melhor análise e foi concluído que tanto jovens quanto adolescentes já possuem dívidas.

Palavras-chave: Economia doméstica. Planejamento financeiro. Finanças Pessoais. Educação financeira.

\section{RESEARCH WITH ADOLESCENTS AND YOUNG PEOPLE ON PERSONAL FINANCIAL MANAGEMENT}

\begin{abstract}
The present work has as its theme the personal financial management, where the main objective is to identify the financial literacy level of adolescents and young people between 15 and 21 years old and how they behave in relation to their income, consumption, and expenses. The choice of this theme arose from the need to understand the main doubts of adolescents and young adults at the beginning of their financial lives, who have income. The aim of this initiative is to make the subject a more natural and present subject, in the family nucleus, as well as approach the subject in a technological way in relation to the target audience through the adopted research tools. Therefore, this article intends to disseminate the results of the research. identify the level of financial literacy and list the main doubts of adolescents in the context of personal financial management. We made the research available through an online questionnaire with the Google Forms tool and the project was presented to the target audience through partner institutions such as the Presidente Prudente Mirim Guard and through the researcher's social networks. After applying the questionnaires, the answers were divided into two groups for better analysis, and it was concluded that both young people and adolescents already have debts.
\end{abstract}

Keywords: Domestic economy. Financial planning. Personal finances. Financial education.

\section{INTRODUÇÃO}

A alfabetização financeira vem ocupando, atualmente, grande destaque na mídia, em parte, decorrente da pandemia do novo coronavírus.
Diversos setores da economia mundial tiveram baixas históricas assim como as bolsas de valores ao redor do mundo. Diante das incertezas da extensão da pandemia ao longo do tempo bem 
como a disponibilidade de uma vacina, Abreu (2020) aponta que o planejamento financeiro contribui para a recuperação dos efeitos negativos e do delicado momento pelo qual passa a economia.

Entretanto a alfabetização financeira é quase inexistente. Prova disso, é o percentual de famílias endividadas, que de acordo com a pesquisa Endividamento e Inadimplência do Consumidor (PEIC 2020), realizada pela Confederação Nacional do Comércio de Bens, Serviços e Turismo em outubro de 2020, que relataram ter dívidas (cheque pré-datado, cartão de crédito, cheque especial, carnê de loja, crédito consignado, empréstimo pessoal, prestação de carro e de casa) alcançou $66,5 \%$ em outubro, a segunda queda seguida, após ter alcançado a maior proporção da série histórica em agosto de 2020 (67,5\%). Houve redução de 0,7 ponto percentual em relação aos $67,2 \%$ observados em setembro, mas aumento de 1,8 ponto percentual comparativamente aos $64,7 \%$ de outubro de 2019.

Do mesmo modo, é alarmante o grau de endividamento entre os jovens de 18 a 24 anos que possuem renda. De acordo com os dados da Confederação Nacional de Dirigentes Lojistas (CNDL) e do Serviço de Proteção ao Crédito (SPC Brasil) retirados da pesquisa "Hábitos dos brasileiros em relação ao uso do dinheiro 2018", 19\% dos brasileiros nessa faixa etária estão inadimplentes. Sendo que, é nessa fase que lidam com questões importantes de carreira, futuro, formação de novos núcleos familiares e inseguranças.

Existem ainda, aqueles que precisam da ajuda de terceiros para complementar os recursos necessários para pagar suas contas, conforme a "Pesquisa de Endividamento e Inadimplência do Consumidor" realizada pela Confederação Nacional do Comércio de Bens, Serviços e Turismo em outubro de 2020, constando que $17,1 \%$ relatam que sempre ou quase sempre tomam dinheiro emprestado (cheque especial, cartão de crédito etc.) para conseguir pagar contas. Entre os jovens o percentual salta para $23,9 \%$. A pesquisa envolveu 805 consumidores acima de 18 anos, de ambos os gêneros, nas 27 capitais do país, de todas as classes sociais.

Frente ao cenário de elevado grau de endividamento das famílias brasileiras, em especial os jovens, este trabalho propõe identificar o nível de alfabetização financeira dos adolescentes de 15 a 21 anos da região de Presidente Prudente - SP em relação as decisões de poupança e gasto.

A presente pesquisa propõe, inicialmente, e concomitante ao levantamento de dados, também a alfabetização financeira - inicial - dos adolescentes, por meio da aplicação de um questionário sócio informativo, que pode induzilos a começarem a elaborar alguma forma de se planejar financeiramente, objetivando, no futuro, que esses adolescentes consigam atingir suas metas e projetos.

$\mathrm{O}$ atual momento pandêmico do Covid19 , trouxe novos desafios a todos em decorrência do retrocesso do crescimento econômico, com baixa geração de novos empregos e aumento do desemprego. Consequentemente, urge uma preparação maior em termos de organização pessoal, tanto em termos do orçamento financeiro das famílias, quanto no que tange ao orçamento financeiro das empresas.

No entanto, conversar sobre renda e organização financeira na sociedade ainda é um tabu, de acordo com levantamento feito pelo eMoney (2019) os indivíduos não se sentem confortáveis para conversar sobre dinheiro.

Partindo do pressuposto de que, de maneira geral, os jovens ainda não fazem um necessário planejamento financeiro, esse planejamento financeiro - se faz necessário. Necessário no sentido de contribuir para que esses jovens possam se juntar a outros jovens, para, entre outros ideais, formar núcleos familiares mais sólidos do ponto de vista do estruturamento financeiro e até mesmo se aventurar no mundo do empreendedorismo, o que de certa maneira, justifica, ainda mais, a necessidade de pesquisas que se proponham à disseminação de conhecimentos que envolvam o planejamento financeiro, considerando toda a complexidade do mercado financeiro e suas múltiplas interligações sociais, culturais e econômicas.

\section{MÉTODOS}

A metodologia desse artigo foi realizada, inicialmente por meio de uma pesquisa exploratória utilizando como base a monografia intitulada "PESQUISA COM ADOLESCENTES E JOVENS DAS CIDADES DE PRESIDENTE PRUDENTE E REGENTE FEIJÓ - SP SOBRE GESTÃO FINANCEIRA PESSOAL", utilizando revisão bibliográfica sobre a temática em questão, onde 
a mesma pesquisa contou com posterior coleta, tabulação e análise de dados.

\section{RESULTADOS}

Com base nos resultados da pesquisa "PESQUISA COM ADOLESCENTES DAS CIDADES DE PRESIDENTE PRUDENTE E REGENTE FEIJÓ - SP SOBRE GESTÃO FINANCEIRA PESSOAL", as respostas foram divididas em duas faixas etárias de idade: de 15 a 17 anos versus 18 a 21 anos, posto que é de senso comum acreditar que a idade pode influenciar diretamente no nível de alfabetização financeira dos participantes, de acordo com a vivencia familiar da pesquisadora.

Em ambos os universos, o público alcançado foi majoritariamente feminino, demonstrando maior interesse sobre o tema.

Os dois universos da pesquisa demonstraram possuir um bom nível de educação financeira, pois em ambos a maioria dos participantes acha que deveria ajudar em casa mesmo que não precise e/ou não o faça.

Outro dado importante, entre os adolescentes é maior a porcentagem daqueles que exercem alguma forma de trabalho informal, sendo que $51,7 \%$ dos participantes dessa faixa etária estão enquadrados como trabalhadores informais. Já entre os jovens essa taxa cai para $17,6 \%$. Somente $5 \%$ dos adolescentes possuem uma renda formal, uma taxa que pode ser considerada baixa, de forma a demonstrar a vulnerabilidade desses adolescentes diante do mercado de trabalho versus a necessidade familiar de dinheiro e/ou diante de projetos pessoais deles.

Contudo, os dados quando divididos nesses dois universos, demonstram que os jovens são recém alfabetizados financeiramente. Prova disso, são os resultados da questão 11, na qual foi questionado se os participantes organizam sua renda, sendo que $65,5 \%$ dos adolescentes versus $80 \%$ dos jovens organizam suas rendas.

Os jovens também formam a maioria quanto a colaboração nas despesas familiares, podendo ser 0 presente fato uma das consequências da pandemia. Posto que $65,5 \%$ dos adolescentes e $75,2 \%$ dos jovens contribuem ou entregam $100 \%$ de sua renda aos responsáveis, para ajudar nos gastos familiares, totalizando uma diferença de 9,7 pontos percentuais entre os dois grupos.

Foi constatado que no grupo dos jovens, $67 \%$, usam mais o cartão de crédito dos responsáveis para consumir, já entre o grupo dos adolescentes esse percentual cai para $55,1 \%$.

Entretanto, podemos considerar elevado o percentual de adolescentes que usam o cartão de crédito dos responsáveis, sendo interessante identificar, em uma nova pesquisa posterior, qual o nível de acesso desses adolescentes à um produto financeiro tão caro, devido as taxas de juros aplicadas.

Outro dado despertou a atenção, o percentual de jovens e adolescentes endividados (com dívidas em seu nome ou no nome de terceiros) são próximos e de certa forma de grau elevado para a faixa etária estudada, pois são $24,3 \%$ dos adolescentes e $29,4 \%$ dos jovens.

Tanto esses adolescentes quanto esses jovens, no futuro próximo adentrarão a fase adulta com dívidas contraídas, podendo dificultar a qualidade de vida desse individuo, pois de acordo com a bibliografia aqui exposta, o estresse causado pela má gestão dos recursos financeiros pessoais contamina o indivíduo e aqueles próximos a ele.

Os resultados da pesquisa também indicaram que os jovens ganham mais do que os adolescentes, 57 jovens estão na faixa dos que recebem entre 1 salário-mínimo até mais do que um salário-mínimo e meio. Já entre os adolescentes é maior a taxa de participantes que ganham entre as faixas de menor ou igual a um salário-mínimo até um salário-mínimo, são 27 adolescentes que se enquadram dentro dessa faixa.

O resultado revela conformidade com a questão sobre a definição da renda dos participantes, já que trabalhos informais não possuem um "salário-mínimo" previamente estipulado. Diferente do trabalho formal, que também age como instrumento de proteção, tanto para o indivíduo quanto para a empresa.

Em ambos os universos da pesquisa, a maioria das famílias estão na faixa de recebimentos entre 2 salários-mínimos até maior ou igual 3 salários-mínimos.

Contudo, com base nas referências bibliográficas aqui apresentadas, esse resultado indica que as famílias estão vulneráveis financeiramente, já que o salário-mínimo necessário estipulado pelo DIEESE (2021) para o ano de 2021 é de $R \$ R \$ 5.315,74$.

Outro fator atenuante é o recorde histórico de brasileiros desocupados, de acordo com a Pesquisa Nacional por Amostra de Domicílios Contínua (PNAD Contínua) realizada 
pelo IBGE (2021) e divulgada em abril de 2021, 14,4 milhões de brasileiros estão desocupados.

Quanto ao nível de escolaridade dos pais e/ou responsáveis dos participantes, nos dois grupos de idade o nível demonstrou ser baixo, sendo que, esse índice juntamente com a pandemia do novo coronavírus pode ajudar a estratificar ainda mais os escolhidos para postos de trabalho.

Em números absolutos, somente 8 adolescentes do total de 29 responderam que os pais e/ou responsáveis possuem ensino superior ou ensino técnico. Entre os jovens, somente 37 de 85 responderam que os pais e/ou responsáveis possuem ensino técnico ou superior.

Pode-se concluir também que os jovens poupam mais do que os adolescentes, existindo uma diferença percentual de $17,4 \%$ entre os dois universos.

Continuando a construção do perfil dos participantes da pesquisa, foi possível observar que entre os dois grupos, existe uma ligeira diferença entre os que compram por impulso e os que analisam com calma se realmente precisam daquilo.

Os dados demonstram que 70 de 85 jovens pensam com calma no que vão adquirir. Já entre os adolescentes, 15 afirmam pensar com calma de um total de 29 respostas.

Para fins de melhor compreensão, em percentual, $82 \%$ dos jovens analisam com calma frente a somente $51 \%$ dos adolescentes. Esse resultado indica um certo grau de impulsividade na hora de fazer compras por parte dos adolescentes.

Também foi identificado que os jovens, $57,6 \%$ são mais analistas quanto ao preço a prazo e o preço à vista dos produtos que compram em comparação aos adolescentes, onde somente $27,5 \%$ verificam o diferencial de preço dos produtos que compram.

Bem como na questão de "sentir" a diferença de preço nos produtos do supermercado, os jovens são mais atentos a essa variação. Somente $18 \%$ dos jovens não notam, essa diferença ou não vão ao supermercado, o número sobe entre os adolescentes, $31 \%$ deles não "sentem" a diferença de preço.

Entretanto, são números bons, considerando o fato de que a maioria dos participantes da pesquisa estarem atentos as oscilações de preço, indicando assim, uma melhor consciência financeira deles e o início de um entendimento superficial sobre o termo inflação, na prática.

Com o propósito de identificar se os participantes da pesquisa estão colocando conhecimentos financeiros em prática, foram destacadas quatro questões que se complementam.

A primeira questão, se tratava de sonhar, almejar alguma conquista e em qual espaço de tempo o participante pretende conquistar esses sonhos.

Ao contrário das premissas preliminares da pesquisadora, $48 \%$ dos adolescentes possuem sonhos a médio e longo prazo, demonstrando pensar no futuro. A porcentagem é positiva e ainda maior entre os jovens, pois $60 \%$ deles possuem sonhos a médio e longo prazo. Sonhos esses que demandam um mínimo de planejamento financeiro.

$\mathrm{Na}$ próxima pergunta, quando questionados se $\mathrm{o}$ planejamento financeiro poderia ajudá-los a conquistar esses sonhos e tanto os adolescentes quanto os jovens, ou seja, $100 \%$ deles acreditam que sim.

Como já dito aqui anteriormente, de nada adianta conhecer aspectos sobre a educação financeira, se não houver, porém a sua aplicação, de fato, em sua realidade.

Com isso em mente, foi perguntado aos participantes se estavam efetuando o planejamento financeiro para conquistar seus sonhos.

Aqui se encontra a disparidade entre os universos da pesquisa, $60 \%$ dos jovens estão se organizando financeiramente e quanto aos adolescentes, somente $48 \%$ deles se organizam.

Buscando compreender com o que gastariam o dinheiro que podem ganhar/poupar, foi formulada uma questão na qual poderiam marcar mais de uma opção numa lista de itens previamente selecionados.

Entre os jovens, a maioria busca investir em educação. Esse desejo de investir em educação, vai desde cursos profissionalizantes e/ou técnicos, como de idiomas e até no ensino superior.

E entre os adolescentes, uma grande parcela deseja obter sua Carteira Nacional de Habilitação e adquirir seu primeiro veículo. Também foram relatados desejos de aquisição de roupas novas. 


\section{DISCUSSÕES}

Assim, compreende-se que, existe diferença entre os termos educação financeira e alfabetização financeira. Enquanto o termo, educação financeira, refere-se as boas práticas de planejamento financeiro pessoal; alfabetização financeira engloba a real aplicação no cotidiano destes conhecimentos.

A partir dos dados coletados, com base na revisão bibliográfica, observa-se que os adolescentes e jovens que integraram a amostragem da pesquisa nos municípios de Presidente Prudente e Regente Feijó são educados financeiramente.

Os adolescentes de 15 a 17 anos, em sua grande maioria são mais imediatistas, consumistas, menos poupadores e não colocam o planejamento financeiro que desenvolveram em prática no dia a dia, conforme apontado no tópico (C) Introdução.

\section{AGRADECIMENTOS}

Agradeço a instituição de ensino e pesquisa UNOESTE por todo o trabalho de fomentar a pesquisa em nossa região e pela oportunidade de aprimoramento e divulgação do presente artigo que teve como base a monografia "PESQUISA COM ADOLESCENTES E JOVENS DAS CIDADES DE PRESIDENTE PRUDENTE E REGENTE FEIJÓ - SP SOBRE GESTÃO FINANCEIRA PESSOAL".

Ao final, agradeço a Deus, por mais que eu não enxergue seus propósitos, me faço aqui instrumento de vossa vontade.

\section{REFERÊNCIAS}

ABREU, W. R. A. Gestão financeira em tempos de crise.SEBRAE ARTIGOS. Disponível em: https://www.sebrae.com.br/sites/PortalSebrae/a rtigos/gestao-financeira-em-tempos-decrise,af7868e2ce8f0710VgnVCM1000004c00210a RCRD. Acesso em: 25 fev. 2021.

ANDRADE, J. et al. Educação financeira: uma análise de grupos acadêmicos. E\&G Economia e Gestão, Belo Horizonte, v. 18, n. 49, jan./abr., $2018 . \quad$ https://doi.org/10.5752/P.1984$\underline{6606.2018 \mathrm{v} 18 \mathrm{n} 49 \mathrm{p} 103-121}$

LAKATOS M. E., MARCONI A. M. . Introdução à metodologia do trabalho científico. 8. ed. São Paulo: Atlas 2003.

CAMPOS, C. et al. Reflexões sobre a educação financeira e suas interfaces com a educação matemática e a educação crítica. Revistas PUC SP, 2015. Disponível em: https://revistas.pucsp.br/emp/article/view/2567 1/pdf. Acesso em: 12 fev. 2020.

CNC - CONFEDERAÇÃO NACIONAL DO COMERCIO DE BENS, SERVIÇOS E TURISMO. Pesquisa de endividamento e inadimplência do consumidor (Peic). Julho de 2020. p .1-3.Disponível em: http://www.cnc.org.br/editorias/economia/pesq uisas/pesquisa-de-endividamento-einadimplencia-do-consumidor-peic-julho-0. Acesso em: 15 ago.2020.

CNC - CONFEDERAÇÃO NACIONAL DO COMERCIO DE BENS, SERVIÇOS E TURISMO. Pesquisa de intenção de consumo das famílias (ICF). Agosto de 2020. p. 2-3. Disponível em: http://www.cnc.org.br/editorias/economia/pesq uisas/pesquisa-de-intencao-de-consumo-dasfamilias-icf-agosto-de-2020. Acesso em: 30 ago. 2020.

CNDL - CONFEDERAÇÃO NACIONAL DE DIRIGENTES LOJISTAS E SPC BRASIL. Hábitos dos brasileiros em relação ao uso do dinheiro. Fevereiro de 2018. Disponível em: https://www.spcbrasil.org.br/wpimprensa/wpcontent/uploads/2018/03/Analise_educacao_fin anceira_habitos_comportamento_marco_2018.p df. Acesso em: 24 ago. 2020.

DETONI, D. J.; LIMA, M. S. Educação Financeira para Crianças e Adolescentes. In: SIMPÓSIO DE EXCELÊNCIA EM GESTÃO E TECNOLOGIA. 8., local??? Disponível: Acesso em: 24 ago 2020.

DIEESE. DEPARTAMENTO INTERSINDICAL DE ESTATÍSTICA E ESTUDOS SOCIOECONÔMICOS. Pesquisa nacional da cesta básica de alimentos. Salário-Mínimo Nominal e Necessário. Disponível em:

https://www.dieese.org.br/analisecestabasica/sal arioMinimo.html. Acesso em: 22 abr.2021.

EISENSTEIN, E. Adolescência: definições, conceitos e critérios. Adolesc. Saúde. v. 2, n. 2, p. 6-7, 2005.

FOLHAPE. Endividamento entre jovens: 12 milhões de brasileiros, entre 25 e 29 anos, estão inadimplentes. Folhape, 2019. Disponível em: https://www.folhape.com.br/noticias/noticias/ed uca-mais- 
brasil/2019/03/20/NWS,99493,70,1296,NOTICIAS ,2190-ENDIVIDAMENTO-ENTRE-JOVENSMILHOES-BRASILEIROS-ENTRE-ANOS-ESTAOINADIMPLENTES.aspx. Acesso em: 13 fev. 2020.

FUNDAÇÃO SANEPAR. 6 em cada 10 brasileiros não gostam de cuidar das finanças pessoais. Fundação Sanepar, 2018. Disponível em: https://www.fundacaosanepar.com.br/?q=blog/6 -em-cada-10-brasileiros-n\%C3\%A3o-gostam-decuidar-das-finan\%C3\%A7as-pessoais. Acesso em: 20 ago. 2020.

GIL, A. C. Como elaborar projetos de pesquisa. 4. ed. São Paulo: Atlas, 2002.

GONTIJO, J. Coronavírus: cenário atual chama a atenção para a saúde financeira. AEF Brasil Associação de Educação Financeira do Brasil, $2020 . \quad$ Disponível em: https://www.aefbrasil.org.br/index.php/coronavi rus-cenario-atual-chama-a-atencao-para-a-saudefinanceira/. Acesso em: 20 ago. 2020.

GÜNTHER, H. Pesquisa qualitativa versus pesquisa quantitativa: esta é a questão?. Psicologia: Teoria e Pesquisa, v. 22, n. 2, p. 201-209. 2006. Disponível em: http://www.scielo.br/scielo.php?pid=S0102-

37722006000200010\&script=sci_arttext. Acesso em: 13 fev. 2020.

IBGE. INSTITUTO BRASILEIRO DE GEOGRAFIA E ESTATÍSTICA. Pesquisa de orçamentos familiares 2017-2018 (POF). Rio de Janeiro. 2019. Disponível em:

https://biblioteca.ibge.gov.br/visualizacao/livros/ liv101670.pdf. Acesso em: 24 ago. 2020.

IBGE. INSTITUTO BRASILEIRO DE GEOGRAFIA E ESTATÍSTICA. Pesquisa nacional por amostra de domicílios continua. Rio de Janeiro. Primeiro trimestre de 2020. Disponível em: https://biblioteca.ibge.gov.br/visualizacao/period icos/2421/pnact_2020_1tri.pdf. Acesso em: 15 set. 2020 .

IBGE. INSTITUTO BRASILEIRO DE GEOGRAFIA E ESTATÍSTICA. Pesquisa nacional por amostra de domicílios continua. Rio de Janeiro. Segundo trimestre de 2020. Disponível em: https://biblioteca.ibge.gov.br/visualizacao/period icos/2421/pnact_2020_2tri.pdf. Acesso em: 15 sset.2020.
$\mathrm{KOCHE}$, J. C. Fundamentos de metodologia científica: teoria da ciência e prática da pesquisa. 16.ed. Petrópolis: Vozes, 2007.

NOVAES, V. Número de brasileiros endividados chega a maior nível desde 2010. Panrotas, 2020. Disponível em: https://www.panrotas.com.br/mercado/pesquisa s-e-estatisticas/2020/01/numero-de-brasileirosendividados-chega-a-maior-nivel-desde2010_170319.html. Acesso em: 13 fev. 2020.

OCDE. Annual Report - 2005. Disponível em: https://www.oecd.org/about/34711139.pdf. Acesso em: 30/05/2021.

POTRICH, A. et al. Determinantes da alfabetização financeira: análise das influências de variáveis socioeconômicas e demográficas. $\mathbf{R}$. Cont. Fin. - USP, São Paulo, v. 26, n. 69, p. 362377, set./out./nov./dez. 2015. https://doi.org/10.1590/1808-057×201501040

RAE, D. Pesquisa mostra que falar sobre dinheiro é tabu nos círculos sociais. FORBES, 2019. Disponível em: https://forbes.com.br/colunas/2019/08/pesquisa -mostra-que-falar-sobre-dinheiro-e-tabu-noscirculos-sociais/. Acesso em: 20 ago. 2020.

SAVOIAL, J. et al. Paradigmas da educação financeira no Brasil. Revista de Administração Pública, v. 41, n. 6, p. 1121-1141, 2007. Disponível em: http://www.scielo.br/scielo.php?pid=S0034$76122007000600006 \&$ script=sci_arttext. Acesso em: 12 fev. 2020.

SEBRAE - SERVIÇO BRASILEIRO DE APOIO ÀS MICRO E PEQUENAS EMPRESAS. Pesquisa as finanças dos pequenos negócios paulistas em tempos de coronavírus.. Disponível em: https://m.sebrae.com.br/Sebrae/Portal\%20Sebra e/UFs/SP/Pesquisas/Relatorio-FinancasMPEcorona-VF3.pdf Acesso em: 12 nov. 2020.

SEVERINO, A. J. Metodologia do trabalho científico. 22. ed. rev. e ampl. São Paulo: Cortez, 2002.

SILVA, M. et al. Habilidades matemáticas e o conhecimento financeiro no ensino médio. Revista de Contabilidade e Organizações (2018) 
v. 12 p $:$ e147269. 2018

https://doi.org/10.11606/issn.1982-

6486.rco.2018.147269

SILVA, K. L. M. Somos tão jovens!: análise do comportamento financeiro dos jovens e adolescentes no município de ljuí/RS. 2020. 59 f. Trabalho de Conclusão de Curso (Graduação em Administração) - Universidade Regional do Noroeste do Estado do Rio Grande do Sul, ljuí, 2020.

SANTOS, L. S. . A importância da educação financeira nas empresas sob o aspecto da produtividade e da redução dos acidentes de trabalho. Revista Científica Hermes, n. 8, jan./jun., p. 140-149 2013, Disponível em: https://www.redalyc.org/articulo.oa?id=4776478 15008 Acesso em: 12 nov.2020. https://doi.org/10.21710/rch.v8i0.76

VANDERLEY, M. S. et al. Educação financeira na infância e adolescência e seus reflexos na vida adulta: uma revisão de literatura. Int-facit business and technology journal, [S.. I], v. $1, n$. 20, p. 149-166, nov. 2020.

VASCONCELOS, M. A. S.; GARCIA, M. E.; Fundamentos de Economia. 5. ed. São Paulo: Saraiva, 2014. 